"This document is the Accepted Manuscript version of a Published Work that appeared in final form in Applied Catalysis B: Environmental, www.elsevier.com/locate/apcatb, copyright (C2017 Elsevier B.V.after peer review and technical editing by the publisher. To access the final edited and published work see http://www.sciencedirect.com/science/article/pii/S0926337317304976

\title{
Magnetically-actuated mesoporous nanowires for enhanced heterogeneous catalysis
}

\author{
Albert Serrà ${ }^{1, @^{*}, \text { Sergi Grau }}{ }^{\$}$, Carolina Gimbert-Suriñach ${ }^{\$}$, Jordi Sort ${ }^{\perp, \#}$, Josep Nogués ${ }^{\&, \#, *}$, Elisa \\ Vallés $\|, @ *$ \\ "Grup d'Electrodeposició de Capes Primes i Nanoestructures (GE-CPN), Departament de Ciència de \\ Materials i Química Física, Universitat de Barcelona, Martí i Franquès, 1, E-08028, Barcelona, \\ Catalonia, Spain. \\ @ Institute of Nanoscience and Nanotechnology (IN $\left.{ }^{2} \mathrm{UB}\right)$, Universitat de Barcelona \\ \$ Institute of Chemical Research of Catalonia (ICIQ), Barcelona Institute of Science and Technology, \\ Avinguda Països Catalans 16, 43007 Tarragona, Catalonia, Spain. \\ ${ }^{\perp}$ Departament de Física, Universitat Autònoma de Barcelona, E-08193, Bellaterra, Catalonia, Spain. \\ \# ICREA, Pg. Lluís Companys 23, 08010, Barcelona, Spain. \\ \& Catalan Institute of Nanoscience and Nanotechnology (ICN2), CSIC, The Barcelona Institute of \\ Science and Technology, Campus UAB, Bellaterra, E-08193 Barcelona, Spain. \\ *Corresponding Authors: a.serra@ub.edu; josep.nogues@uab.cat; e.valles@ub.edu.
}

ABSTRACT: We study the optimization of the catalytic properties of entirely magnetic CoPt compact and mesoporous nanowires of different diameters $(25-200 \mathrm{~nm})$ by using magnetic actuation. The nanowires are a single-entity, robust, magnetic-catalyst with a huge catalytically-active surface area. We show that apart from conventional parameters, like the size and morphology of the nanowires, other 
factors can be optimized to enhance their catalytic activity. In particular, given the magnetic character of the nanowires, rotating magnetic fields are a very powerful approach to boost the performance of the catalyst. In particular, the magnetic field induces them to act as nano-stirrers, improving the local flow of material towards the active sites of the catalyst. We demonstrate the versatility of the procedure by optimizing (i) the degradation of different types of pollutants (4-nitrophenol and methylene blue) and (ii) hydrogen production. For example, by using as little as $0.1 \mathrm{mg} \mathrm{mL}^{-1}$ of $25 \mathrm{~nm}$ wide CoPt mesoporous nanowires (with $\sim 3 \mathrm{~nm}$ pore size) as catalysts, kinetic normalized constants $k_{n o r}$ as high as 20667 and $21750 \mathrm{~s}^{-1} \mathrm{~g}^{-1}$ for 4-nitrophenol and methylene blue reduction, respectively, are obtained. In addition, activity values for hydrogen production from borohydride are as high as $25.0 \mathrm{~L} \mathrm{H}_{2} \mathrm{~g}^{-1} \mathrm{~min}^{-1}$, even at room temperature. These values outperform any current state-of-the-art proposed catalysis strategies for water remediation reactions by at least 10-times and are superior to most advanced approaches to generate hydrogen from borohydride. The recyclability of the nanowires together with the simplicity of the synthetic method makes this approach (using not only CoPt, but also other mesoporous magnetic catalysts) very appealing for very diverse types of catalytic applications.

\section{Graphical Abstract}

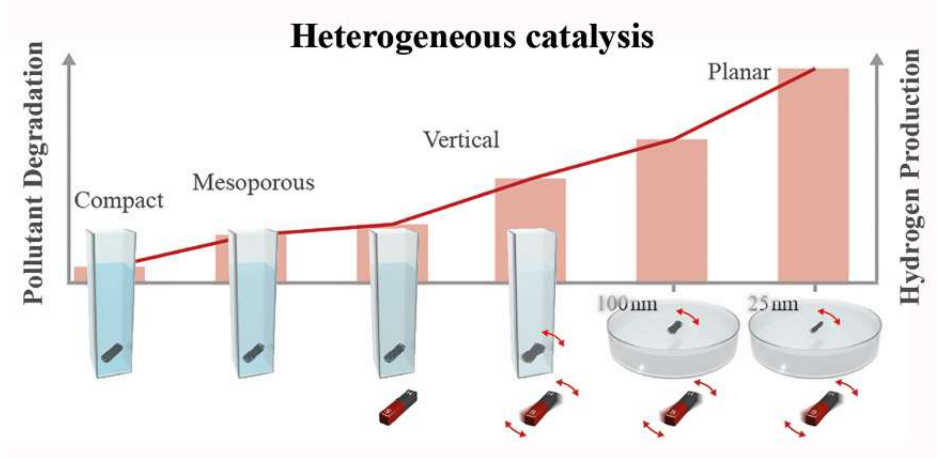

\section{Highlights}

- Magnetic actuation of purely magnetic mesoporous nanowires (NWs) is revealed as a novel and efficient catalysis procedure in reactions of heterogeneous catalysis in environmental and energy fields.

- Mesoporous CoPt NWs are simultaneously effective catalysts itself and the stirring device, using magnetic fields, to catalyse reactions in solution.

- The procedure allows ultra-fast degradation of different types of pollutants. 
- The NWs show very high effectivity for hydrogen generation $\left(25.0 \mathrm{~L} \mathrm{H}_{2} \mathrm{~g}^{-1} \mathrm{~min}^{-1}\right)$ by catalysing the hydrolysis of sodium borohydride using magnetic actuation.

KEYWORDS: mesoporous magnetic nanowires; magnetically-actuated catalysis; water remediation; hydrogen production; catalyst recyclability.

\section{Introduction}

It is well-known that catalysis plays a crucial role in our everyday life and it is one of the pillars of modern chemistry. Most industrial chemical processes (e.g., energy, pharmaceutical, food or material production industries) are based on catalytic processes [1-6]. Similarly, catalysis plays a strategic role in many environmental and energy issues such as air pollution control (e.g., car exhausts), wastewater remediation or hydrogen production [7-12]. Thus, any improvement on the performance of catalytic processes could result in a huge economic and social impact. Consequently, many different types of processes such as microwave-, plasma-, ultrasound-, electric field-, acoustic-, light- or temperatureassisted catalysis, among others, are continuously emerging as promising strategies to enhance these type of reactions [13-22]. Another aspect which is being actively explored to improve heterogeneous catalysis is to increase the surface area of the catalyst, using for example nanostructured materials [2329]. In particular, mesoporous materials, which possess an extraordinarily large specific surface area, have attracted great attention for heterogeneous catalysis in liquid media [30, 31]. Additionally, of all the variables involved in heterogeneously catalysed reactions, effective mass transfer is fundamental to enhance the reaction rate, magnetic stirring bars or mechanical stirrers are usually used to promote the mass transportation efficiency $[32,33]$. However, delicate catalysts might be damaged under vigorous mechanical stirring or catalysts involving magnetic materials may get stuck to the magnetic stirring bars [34].

Strikingly, an aspect that has been somewhat underexploited in catalysis is magnetic actuation on the catalyst itself. In fact, during the 90 s and early 2000s it was shown that magnetic fields could actually control the mass transport in some chemical reactions [35]. In recent years, the important role of magnetic materials in the control of magnetic field induced convection has been established [36, 37]. Other attractive aspects of magnetic fields in catalysis are their influence on the oxidation process of magnetic ions or their effect on the electronic structure of the catalysts [38, 39]. Although lately there has been an increase of the use of magnetic materials in catalytic processes, usually the magnetic counterpart does not play an active role in the catalysis, but it is rather used as a simple means to recover 
the catalyst to recycle and reuse it [40-42]. An appealing aspect of magnetic materials in catalysis, that has been proposed recently, is the concept of magnetically-actuated remote micro-stirrers [43-47]. The use of these magnetic stirrers has been shown to improve diverse types of catalytic processes by favouring the local flow of matter. However, again, in these catalysts the magnetic counterpart does not play an active role in the reaction [43-47]. Moreover, these micro-stirrers are often composites (with both magnetic and catalytic moieties and usually other components), which could make them rather fragile. Moreover, often they require complex synthesis procedures, often involving many steps, making them less attractive for large scale production [43, 47].

It is important to highlight that catalysts based on magnetic ions (e.g., $\mathrm{Fe}, \mathrm{Co}$ or $\mathrm{Ni}$ ) have also started to attract a great deal of attention, although not necessarily due to their magnetic nature but due to their transition-metal character. Namely, they have been proposed as suitable candidates to partially substitute the expensive noble-metal catalysts (e.g., Pt, Au or Pd) by inexpensive alternatives, which in general improve the catalytic performance [48-51]. In particular, the partial substitution of Pt by Co has been shown to result in excellent alternatives for many different types of processes [52-55].

Here we demonstrate that easily-synthesized mesoporous CoPt magnetic nanowires (NWs) can be used as effective magnetically-actuated micro-stirrers to boost diverse types of catalytic reactions (e.g., for 4-nitrophenol and methylene blue degradation or hydrolysis of alkaline sodium borohydride for hydrogen production). These mesoporous NWs constitute a novel simple, all-in-one catalyst (i.e., a strongly catalytically active magnetic material) with a large active area, which can be easily manipulated by magnetic fields. The role of different parameters in the improved catalytic performance is investigated, such as the magnetic field rotation speed, the nanowire morphology and diameter and the reaction geometry. The results show that narrow mesoporous NWs magnetically actuated at high rotation speeds in planar reaction geometry is the optimum combination to achieve outstanding performances in both types of reactions.

\section{Experimental}

\subsection{Electrochemical media.}

The electrochemical media (Table 1) used for synthesising compact or mesoporous NWs were an aqueous solution (W) of $2.5 \mathrm{mM} \mathrm{CoCl}_{2} \cdot 6 \mathrm{H}_{2} \mathrm{O}$ (Carlo Erba, $>98.0 \%$ ) $+1.2 \mathrm{mM} \mathrm{Na}_{2} \mathrm{PtCl}_{6} \cdot 6 \mathrm{H}_{2} \mathrm{O}$ (Alfa Aesar, $98 \%$ ) + $0.1 \mathrm{M} \mathrm{NH}_{4} \mathrm{Cl}$ (Fluka, $99.5 \%$ ) $+10 \mathrm{~g} \mathrm{~L}^{-1} \mathrm{H}_{3} \mathrm{BO}_{3}$ (Merck, > $98 \%$ ) and an ionic liquidin-water (IL/W) microemulsion, respectively. IL/W microemulsions were prepared by mixing the adequate proportion of each component ( $\mathrm{W}$ - aqueous solution -, S - Surfactant, p-octyl poly (ethyleneglycol) phenyl ether a.k.a. Triton X-100 (Acros Organics, 98 \%) -, and IL - Ionic Liquid, 1- 
butyl-3-methylimidazolium hexafluorophosphate a.k.a. bmimPF 6 (Solvionic, $99 \%$ ) -) during 5 min under magnetic stirring (300 rpm) and argon bubbling, leading to a transparent, isotropic, and thermodynamically stable microemulsion $[56,57]$. All solutions were prepared using deionized water (Millipore Q-System) with a resistivity of $18.2 \mathrm{M} \Omega \mathrm{cm}$.

\begin{tabular}{c|ccc} 
Electrochemical media & W/wt. \% & S / wt. \% & IL / wt. \% \\
\hline $\begin{array}{c}\text { Aqueous solution (W) } \\
\text { Ionic Liquid-in-water }\end{array}$ & 100 & - & - \\
microemulsion (IL/W) & 83.8 & 15.1 & 1.1
\end{tabular}

Table 1: Electrochemical media selected for synthesising Co-Pt NWs.

\subsection{Electrochemical synthesis.}

The shape-controlled electrodeposition of compact or mesoporous (double-template electrodeposition) Co-Pt NWs was carried out using a microcomputer-controlled potentiostat/galvanostat Autolab with a PGSTAT30 equipment and GPES software. Commercial polycarbonate (PC) membranes (Millipore Company) with nominal pore sizes of 100 or $200 \mathrm{~nm}$ and alumina membranes (SmartPor Membranes $G m B H$ ) with a nominal pore size of $25 \mathrm{~nm}$ were used as working electrodes. The pores of the membranes act as templates for the shape-controlled growth of nanostructured wires, where aqueous or IL/W microemulsion media lead to either compact or mesoporous NWs. The use of microemulsions allows the formation of a three-dimensionally interconnected network of open mesopores along the entire area of NWs $[31,56]$. However, in order to use the membranes as a working electrode a conductive layer on one side is necessary. Therefore, vacuum evaporation was used to coat the membrane on one side with around a $100 \mathrm{~nm}$-thick gold layer. The electrodeposition process was performed at $25{ }^{\circ} \mathrm{C}$, using a three-electrode electrochemical system - polycarbonate/Alumina membranes, Pt spiral, and $\mathrm{Ag} / \mathrm{AgCl} / \mathrm{KCl}(3 \mathrm{M})$ electrodes, as a working, counter and reference electrodes, respectively - , in potentiostatic mode (at $-1.0 \mathrm{~V}$ ). The electrochemical media was deaerated by argon bubbling before each experiment and maintained under argon atmosphere during it.

After the deposition, the samples were dried and weighted several times until a constant weight in vacuum conditions was attained in order to determine the total mass of synthesized NWs. Then, the NWs were released from the membrane first removing the Au layer using a saturated solution of $I_{2} / \mathrm{I}^{-}$ and subsequently dissolving polycarbonate or alumina membrane with either chloroform (x10) or $\mathrm{NaOH}(1 \mathrm{M})$, and then washing with ethanol (x5) and water (x5) under flashing ultrasound stirring. 


\subsection{Materials characterization.}

The morphology of the Co-Pt NWs was examined by using transmission electron microscopy (Jeol 2100 ) and the elemental composition was determined by energy-dispersive X-ray analysis incorporated in a JSM-7100 scanning electron microscopy.

Hysteresis loops of the compact and mesoporous NWs (while still embedded in the membrane) were measured at room temperature using a vibrating sample magnetometer from Micro-Sense (LOTQuantum Design), with a maximum external magnetic field of $20 \mathrm{kOe}$, applied either along or perpendicular to the NWs axis.

The electrochemical surface area (ECSA) values of the CoPt NWs were determined by using cyclic voltammetries in $0.5 \mathrm{M} \mathrm{H}_{2} \mathrm{SO}_{4}$ at $20 \mathrm{mV} \mathrm{s}^{-1}$ at $25^{\circ} \mathrm{C}$. For each $\mathrm{NW}$ type, $5 \mu \mathrm{L}$ of a NWs ink $(0.1 \mathrm{mg}$ $\left.\mathrm{mL}^{-1}\right)$ was dropped on the surface of a glassy carbon (GC) rod $\left(0.031 \mathrm{~cm}^{2}\right.$ in diameter) and dried under nitrogen. It is well known that for Pt base nanostructures, the ECSA can be obtained from the total charge passed during hydrogen adsorption/desorption (after accounting for the double layer capacity and assuming that the charge required to oxidise a mono-layer of hydrogen on bright Pt is $210 \mu \mathrm{C} \mathrm{cm}^{-}$ ${ }^{1}$ ) by using the following equation (Eq. 1) [31, 56]:

$$
E C S A=\frac{Q_{\text {measured }}}{Q_{\text {theoretica }} \cdot m_{\text {CoPt }}} \quad \text { (Eq. 1) }
$$

Where $\mathrm{Q}_{\text {measured }}$ is the charge measured by integration of a voltammetric peak associated with an adsorption process, $Q_{\text {theoretical }}$ is the charge required for monolayer coverage of $1 \mathrm{~cm}^{2}$ of electrode surface by the adsorbed species and $m_{C o P t}$ is the mass of catalyst.

X-ray powder diffraction (XRPD) measurements were acquired with a PANalytical X'Pert Pro MPD diffractometer in the Bragg-Brentano reflection $\theta / 2 \theta$ geometry, at $45 \mathrm{kV}, 40 \mathrm{~mA}$, and $\lambda=$ $1.5406 \AA\left(\mathrm{Cu} \mathrm{K}_{\alpha 1}\right)$. The samples were prepared by drop casting and solvent evaporation of the catalyst ink on a monocrystalline Si holder. XRPD patterns were obtained after $\theta / 2 \theta$ scans from 20 to $120^{\circ} 2 \theta$, with a step size of $0.0172^{\circ}$, a measuring time of 200 seconds per step. Note that the measurements were repeated to acquire sufficient statistics. The data were analysed using the X'Pert HighScore Plus software.

X-Ray photoemission spectroscopy (XPS) measurements were carried out in ultra-high vacuum using a PHI ESCA-550 multi-technique system (Physical Electronics), with a monochromatic x-ray source $\left(\mathrm{Al} \mathrm{K} \mathrm{K}_{\alpha}\right.$ line of $1486.6 \mathrm{eV}$ energy and $350 \mathrm{~W}$ ) placed perpendicular to the analyser axis and calibrated using the $\mathrm{Ag} 3 \mathrm{~d}_{5 / 2}$ line with a full width at half maximum of $0.8 \mathrm{eV}$. The analysed area was a circle 0.8 
$\mathrm{mm}$ in diameter, and the selected resolution for the spectra was $187.85 \mathrm{eV}$ of pass energy and $0.8 \mathrm{eV}$ per step for the general spectra.

\subsection{Water remediation.}

The reduction of 4-nitrophenol and methylene blue was chosen as model reactions to test the catalytic activity of the compact and mesoporous Co-Pt NWs. In both reactions the temporal evolution of the catalytic reaction was tracked $e x$-situ by UV-visible spectroscopy in a quartz cuvette with an optical length of $1 \mathrm{~cm}$ using a UV-1800 Shimadzu UV-Visible spectrophotometer. All of the experiments were conducted at room temperature. For these experiments, two different pollutants were selected:

(i) 4-nitrophenol: $300 \mu \mathrm{L}$ of 4-nitrophenol $(0.7 \mathrm{mM}$ solution) was diluted with $1 \mathrm{~mL}$ of Millipore water, followed by the addition of $1 \mathrm{~mL}$ of freshly prepared ice-cold $\mathrm{NaBH}_{4}$ solution $(0.5 \mathrm{M})$, and a given amount of the prepared catalyst ink $\left(0.1 \mathrm{mg} \mathrm{mL}^{-1}\right)$. As a result, the bright yellow solution gradually fades as the reaction progresses. The absorption peak intensity at $400 \mathrm{~nm}$ was used to quantify the temporal evolution of the 4-nitrophenol concentration.

(ii) Methylene blue: $300 \mu \mathrm{L}$ of methylene blue $(0.4 \mathrm{mM}$ solution) was diluted with $1 \mathrm{~mL}$ of Millipore water, followed by the addition of $1 \mathrm{~mL}$ of freshly prepared ice-cold $\mathrm{NaBH}_{4}$ solution $(2.3 \mathrm{mM})$, and a given amount of the prepared catalyst ink $\left(0.1 \mathrm{mg} \mathrm{mL}^{-1}\right)$. As a result, the dark blue solution gradually fades as the reaction progresses. The absorption peak intensity at $662 \mathrm{~nm}$ was used to quantify the temporal evolution of the concentration of methylene blue.

\subsection{Optimization of the catalytic performance.}

Importantly, four different reaction conditions were pursued:

(i) Silent, where no specific actuation was carried out during the reduction reaction.

(ii) Magnetic actuation, where the NWs were influenced by an external rotatory magnetic field ( $\sim 00 \mathrm{Oe}$ - magnetic stirrer RH digital - IKA) at various ration speeds.

(iii) Mechanical actuation, where the NWs were mechanically stirred at $100 \mathrm{rpm}$ using a Metrohm 622 rod stirrer.

(iv) Magneto-mechanical actuation, where the NWs were simultaneously mechanically (100 rpm) and magnetically (100 rpm) stirred.

Moreover, the effects of the reaction geometry was also assessed: 

$26 \mathrm{~mm}^{3}$ shape (see Fig. 2).

(ii) Planar geometry, where the container used was "cylindrical planar" with a $\pi \times 17^{2} \times 3 \mathrm{~mm}^{3}$ shape or a microdroplet $(\sim 0.1 \mathrm{~mL})$ (see Fig. 2).

In the catalytic test, the concentrations of $\mathrm{NaBH}_{4}$ in all the reactions are fixed at $\sim 2380$-times and $\sim 19$ times higher that of 4-nitrophenol and methylene blue, respectively. Therefore, an excess amount of reductant $\mathrm{NaBH}_{4}$ was used and, consequently, the reduction rate constant can be calculated based on pseudo-first-order kinetics. The apparent kinetic rate constant $\left(k_{a p p}\right)$ is proportional to the total surface area of the catalyst, which can be estimated based on the regression of the slope from the logarithm plot (Eq. 2)

$$
\left(\frac{d C_{t}}{d t}=-k_{a p p} C_{t}\right) \rightarrow \ln \left(\frac{C_{t}}{C_{0}}\right)=\ln \left(\frac{A_{t}}{A_{0}}\right)=-k_{a p p} t \text { (Eq. 2) }
$$

Moreover, in order to quantitatively compare with other catalysts, the normalized rate constant $\left(k_{\text {nor }}\right)$ was also determined, which is associated with the amount of catalyst, i.e., $k_{n o r}=k_{\text {app }} / m_{C o-P t}$. In some cases, the catalytic activity was evaluated by the degradation efficiency after $60 \mathrm{~s}$ by the relation between $\left(A_{60} / A_{0}\right)$. Lastly, in the microscopic systems, the colour change of blue (methylene blue) or yellow (4-nitrophneol) to colourless was a direct indicator of the reaction progress, i.e., the catalytic activity.

\subsection{Hydrogen production.}

The hydrolysis of sodium borohydride (Eq. 3) was selected to test the catalytic activity of the compact and mesoporous $\mathrm{Co}-\mathrm{Pt}$ NWs towards hydrogen generation.

$$
\mathrm{NaBH}_{4}+2 \mathrm{H}_{2} \mathrm{O} \rightarrow \mathrm{NaBO}_{2}+4 \mathrm{H}_{2} \text { (Eq. 3) }
$$

An alkaline-stabilized solution $4.2 \mathrm{mM}$ sodium borohydride (adjusted to $\mathrm{pH}=13$ using $\mathrm{NaOH} 1 \mathrm{M}$ ), was prepared. Under these conditions, the self-hydrolysis of borohydride is minimized. Then the CoPt catalyst - $24 \mu \mathrm{L}$ of a catalyst ink $\left(0.1 \mathrm{mg} \mathrm{mL}^{-1}\right)$ - was used for hydrogen production in a controlled manner. The generated hydrogen volume and the catalytic activity were measured using a Clark-type hydrogen electrode (Unisense) in the headspace of a gas-tight chamber containing $1 \mathrm{~mL}$ of total solution at $25^{\circ} \mathrm{C}$, which was calibrated with known amounts of hydrogen gas. The experimental conditions were selected to allow a quantitative comparison with previously reported results. Following the results of the catalyst optimization for water remediation (see Results section), both silent and magnetic actuation 
(1200 rpm) in both vertical and planar geometry reactor conditions for compact and mesoporous CoPt NWs were attempted.

\section{Results}

\subsection{CoPt nanowires.}

To evaluate the role of catalyst morphology, two types of Co-rich, $\mathrm{Co}_{66 \pm 3} \mathrm{Pt}_{34 \pm 3}, \mathrm{NWs}, 1.2 \pm 0.3 \mu \mathrm{m}$ in length and with three different diameters $(25,100$ and $200 \mathrm{~nm})$, were electrochemically synthesized (see Experimental) [54, 55]. As can be seen in Figure 1a, b and Table S1, for the $100 \mathrm{~nm}$ NWs, while one type of nanowire is compact (with a smooth surface), the other one has a mesoporous morphology with an interconnected network of pores (with a pore size of about $3.1 \pm 0.9 \mathrm{~nm}$ and an extraordinary high surface area [electrochemically active surface area (ECSA)] of $255 \mathrm{~m}^{2} \mathrm{~g}^{-1}$ - Figure $1 \mathrm{~d}$ and Table S1). Importantly, the elemental maps of the CoPt NWs (Figures 1a, b) show that Co and Pt are homogeneously distributed along the area of both types of NWs.

Both types of NWs are magnetic at room temperature with somewhat similar magnetic characteristics, with the easy axis along the nanowire axis (Figure 1c).

The crystal structure of the CoPt NWs was probed by using x-ray diffraction (XRD) (Figure 1e). From the patterns three families of peaks can be identified: $f c c \mathrm{Au}$, corresponding to some remaining gold in the NWs from the working electrode (highlighted by dotted green arrows), $f c c \mathrm{CoPt}_{3}(\mathrm{Pm}-3 \mathrm{~m})$ (highlighted by dotted red arrows) and a hexagonal $h c p$ CoPt phase $\left(\mathrm{P}_{3} \mathrm{mmc}\right.$ ) (marked by its Miller indices). Note that this latter phase corresponds to $h c p$ Co but very distorted due to the incorporation of Pt atoms in the crystalline lattice. Since the patterns of compact and mesoporous NWs are almost identical, it is clear that they have analogous crystalline structures, composed of polycrystalline cubic and hcp phases. Note that similar crystalline structures have been reported for electrodeposited CoPt films and nanostructured materials $[58,59]$. The bimetallic nature of the prepared NWs is further confirmed by XPS analysis. The high-resolution scans of the XPS spectra (Figure 1f) show for Pt double peaks with binding energies of $71.80 \mathrm{eV}\left(4 \mathrm{f}_{7 / 2}\right)$ and $75.21 \mathrm{eV}\left(4 \mathrm{f}_{5 / 2}\right)$, clearly shifted from the standard values for pure Pt (i.e., 71.20 and $74.53 \mathrm{eV}$ ). These values are consistent with the formation of a CoPt allow since Pt $4 \mathrm{f}$ peaks are known to change to higher energies when alloying with Co [60]. On the other hand, for Co two peaks at $778.7 \mathrm{eV}\left(\mathrm{Co} 2 \mathrm{p}_{3 / 2}\right)$ and $794.0 \mathrm{eV}$ (Co 2 $\left.\mathrm{p}_{1 / 2}\right)$ are observed, which deviate from the standard values of pure $\mathrm{Co}(778.30 \mathrm{eV}$ and $793.27 \mathrm{eV})$. In concordance to the Pt peaks, the shift in energy of the Co peaks is also consistent with the formation of a CoPt alloy [60]. Note also that although the Co $2 p$ spectra also shows the formation of some cobalt oxides the relative intensity of the 
oxide peaks indicates that only a small fraction of Co is oxidized. It is important to emphasize that the XPS spectra for both types of NWs is almost identical in agreement with the EDX results.
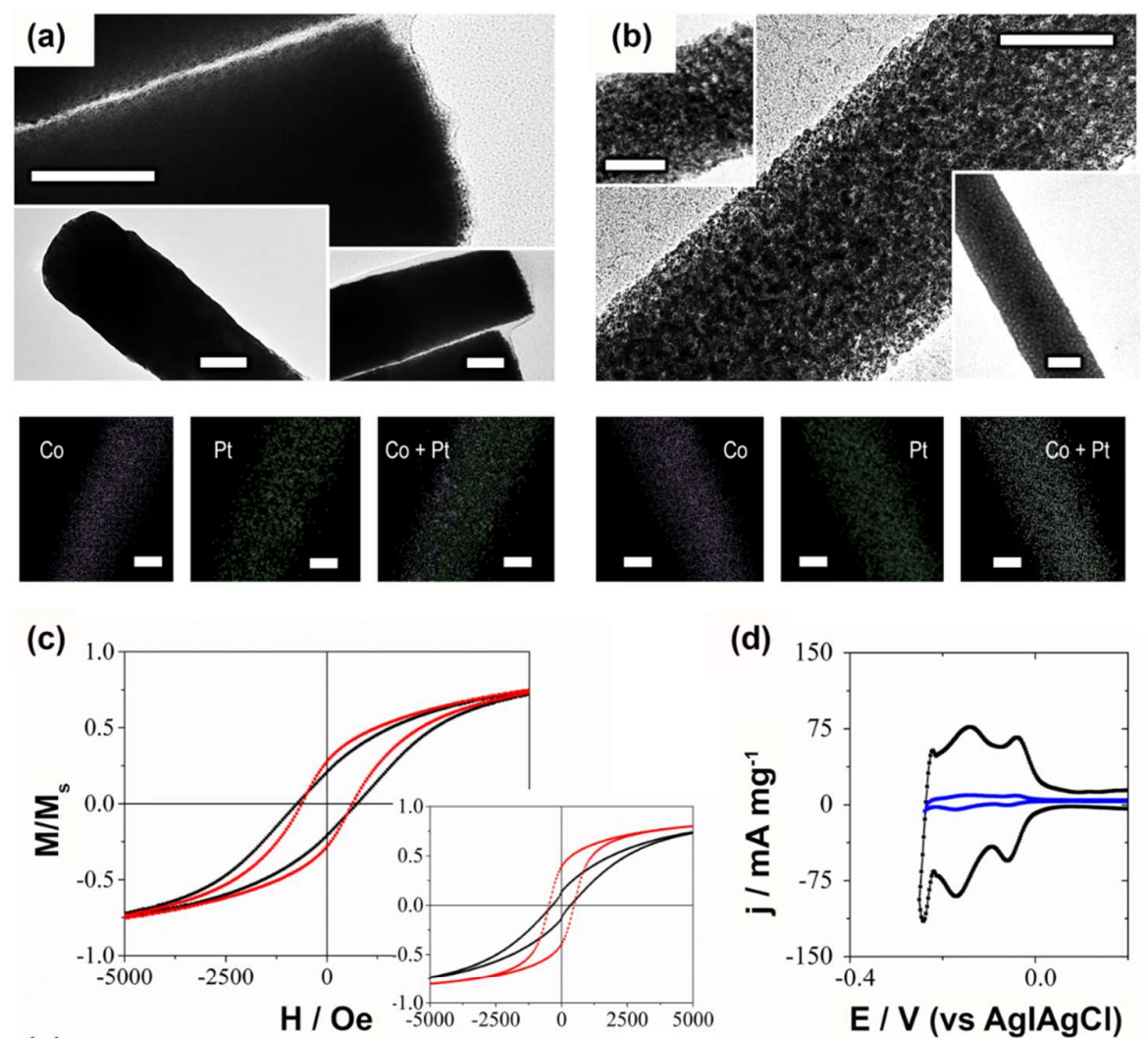

(e)
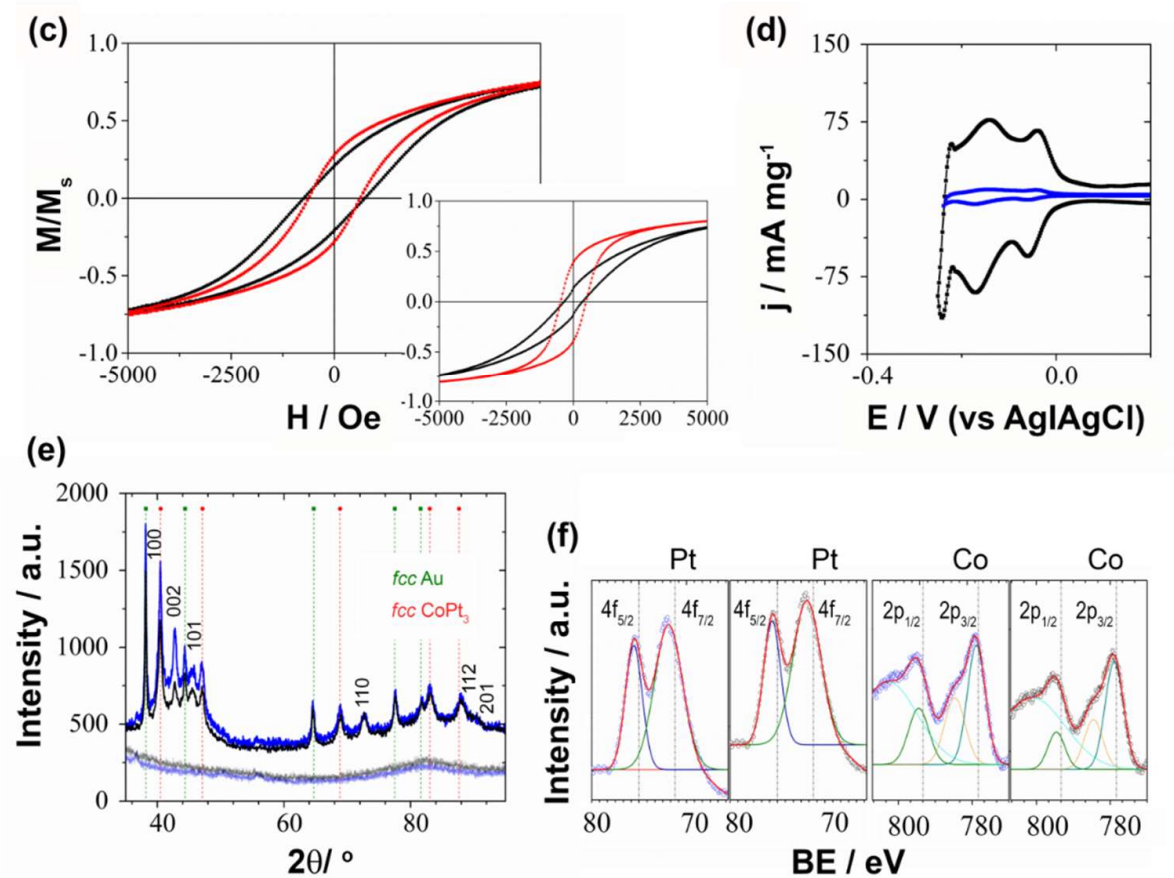

Figure 1: HR-TEM images and elemental mapping of (a) compact and (b) mesoporous $100 \mathrm{~nm}$ NWs. Scale bar $50 \mathrm{~nm}$. (c) Room-temperature parallel (red) and perpendicular (black) to the wire axis hysteresis loop of mesoporous $100 \mathrm{~nm}$ NWs (inset: compact NWs). (d) Cyclic voltammetries of the compact (blue) and mesoporous (black) NWs. (e) XRD patterns of compact (blue) and mesoporous (black) NWs. The index miller indexes of the main peaks of the hexagonal CoPt phase are indicated next to the corresponding peaks. The fcc $\mathrm{Au}$ and $\mathrm{fcc}_{\mathrm{CoPt}}$ phases are highlighted by green and red 
dotted arrows, respectively. At the bottom, Si holder background for each sample is also shown. (f) Pt $4 \mathrm{f}$ and Co 2p XPS spectra from compact (blue) and mesoporous (black) NWs.

\subsection{Water remediation.}

\subsubsection{Basic catalytic activity.}

Before evaluating the catalytic activity, it is important to analyse the adsorption of the two compounds since this may interfere in the degradation process. It is well-known that some materials, particularly when nanostructured, have a strong physical adsorption of pollutants, such as 4-nitrophenol and methylene blue, as a consequence of the surface affinity [61-70]. Consequently, the absorbance of various solutions of each pollutant (without the presence of sodium borohydride) was measured before and after 24 and $48 \mathrm{~h}$ posteriorly to the addition of the NWs (either compact or mesoporous), both in silent mode or in the presence of an external rotatory magnetic field ( 400 Oe and $1200 \mathrm{rpm})$. In all cases, the absorbance remains virtually constant even after $48 \mathrm{~h}$. Therefore we can conclude that the adsorption of these pollutants on the CoPt NWs is not significant. It is also plausible to assume that in the presence of borohydride the capture of pollutants should become even more negligible due to the formation of hydrogen bubbles on the catalyst surface and pollutant degradation.

To test the catalytic activity, the $100 \mathrm{~nm}$ diameter NWs are used to degrade two different types of wellknown wastewater pollutants: 4-nitrophenol and methylene blue. Both types of NWs can trigger the reduction of 4-nitrophenol and methylene blue, confirming the good catalytic properties of the CoPt alloys (see Figure S1, Table S2 and Video S1-S2). Moreover, the mesoporous NWs are clearly more effective than the compact ones in promoting the degradation of 4-nitrophenol and methylene blue, reducing the reaction time by 4 (4-nitrophenol) or 2 (methylene blue), respectively. This is expected from the high surface area of the mesoporous wires, which exposes more active sites to carry out the reaction. In fact, the apparent kinetic constants $k_{a p p}$ (and the mass normalized constant, $k_{n o r}$ ) of both reactions for the mesoporous wires (i.e., without mechanical or magnetic stirring), are already rather large, $k_{n o r}=3807 \mathrm{~s}^{-1} \mathrm{~g}^{-1}$ (4-nitrophenol) and $k_{n o r}=3916 \mathrm{~s}^{-1} \mathrm{~g}^{-1}$ (methylene blue) (Table S2) and comparable with other types of catalysis proposed for these reactions (see Table S4) [43, 71-19]. Importantly, the release of $\mathrm{H}_{2}$ gas in solution by the catalysed hydrolysis of sodium borohydride (see Video S1-2) implies the self-pumping of the fluid medium at the micro and nanoscale levels and, therefore, the enhancement of the mass transport flow. However, the efficiency of the reaction is somewhat restricted by the limited flow of material towards the catalyst, which is basically driven by diffusion. Thus, to favour the mass flow, the same reactions were carried out by applying mechanical stirring at $100 \mathrm{rpm}$ (see Figure S2 and Video S1-2). As expected, mechanical stirring improves the 
reaction kinetics; nevertheless, the gain is somewhat moderate, with a $15-30 \%$ improvement in $k_{n o r}$ for the two types of reactions (see Table S2).

\subsubsection{Magnetically-assisted catalysis.}

As a first assessment of the role of the magnetic field in the catalysis, the reduction of 4-nitrophenol and methylene blue was carried out in the presence of an out-of-plane static field of 200 Oe for the 100 nm NWs. Remarkably, the mere presence of a magnetic field already improves the efficiency of the reaction (Table S2, and Video S3-S4), with an enhanced $k_{n o r}$ by $10-15 \%$. This is in agreement with earlier studies in other types of catalysts where the magnetic fields (and/or field gradients generated by the magnetic catalysis or magnetic objects in close proximity to the catalytic front) enhanced the catalytic activity $[47,80]$. However, based on the chemical nature of both pollutants, the origin of the effect of magnetic fields on the kinetics of degradation is not straightforward. Thus, several experiments were carried out where different out-of-plane static magnetic field intensities (200, 110 and 45 Oe) were applied directly to the reactor (i.e. on the catalyst surface) - similar magnetic field distributions - and an out-of-plane static of 200 Oe was applied at different distances to the reactor base $(0 \mathrm{~cm}-200 \mathrm{Oe}$ and $1.52 \mathrm{~cm}-105$ Oe due to the magnetic reluctance of air) - different magnetic field intensity and different magnetic field distribution. Surprisingly, the presence of a magnetic field increases the efficiency of the reaction, obtaining a similar increase independently to the applied field intensity. However, the distance-i.e. the distribution of the field-seems more determinant, since the improvement of the kinetics is slightly lower (2-4\%) in comparison to a similar magnetic intensity value but directly applied on the catalyst. Actually, due to the nanometric morphology of the mesoporous wires, with multiple edges (which should locally enhance the magnetic field gradients) [36, 37], this latter effect is probably magnified for this type of investigated structure.

To asses a second aspect of the magnetic field actuation, the reactions were performed using a rotating magnetic field (400 Oe) at different speeds. Note that the experiment was carried out using a magnetic

stirring set up; however, no macroscopic magnetic bar was introduced in the container. Instead, the magnetic NWs themselves act as micro-stirring bars by the effect of the rotating field (see Figure 2). As can be seen in Fig 3 (and Figure S3 to S9, Table S2 and Videos S1-2), the rotating magnetic field has an outstanding effect on the effectiveness of the reaction, drastically reducing the reaction time to degrade 4-nitrophenol and methylene blue. 

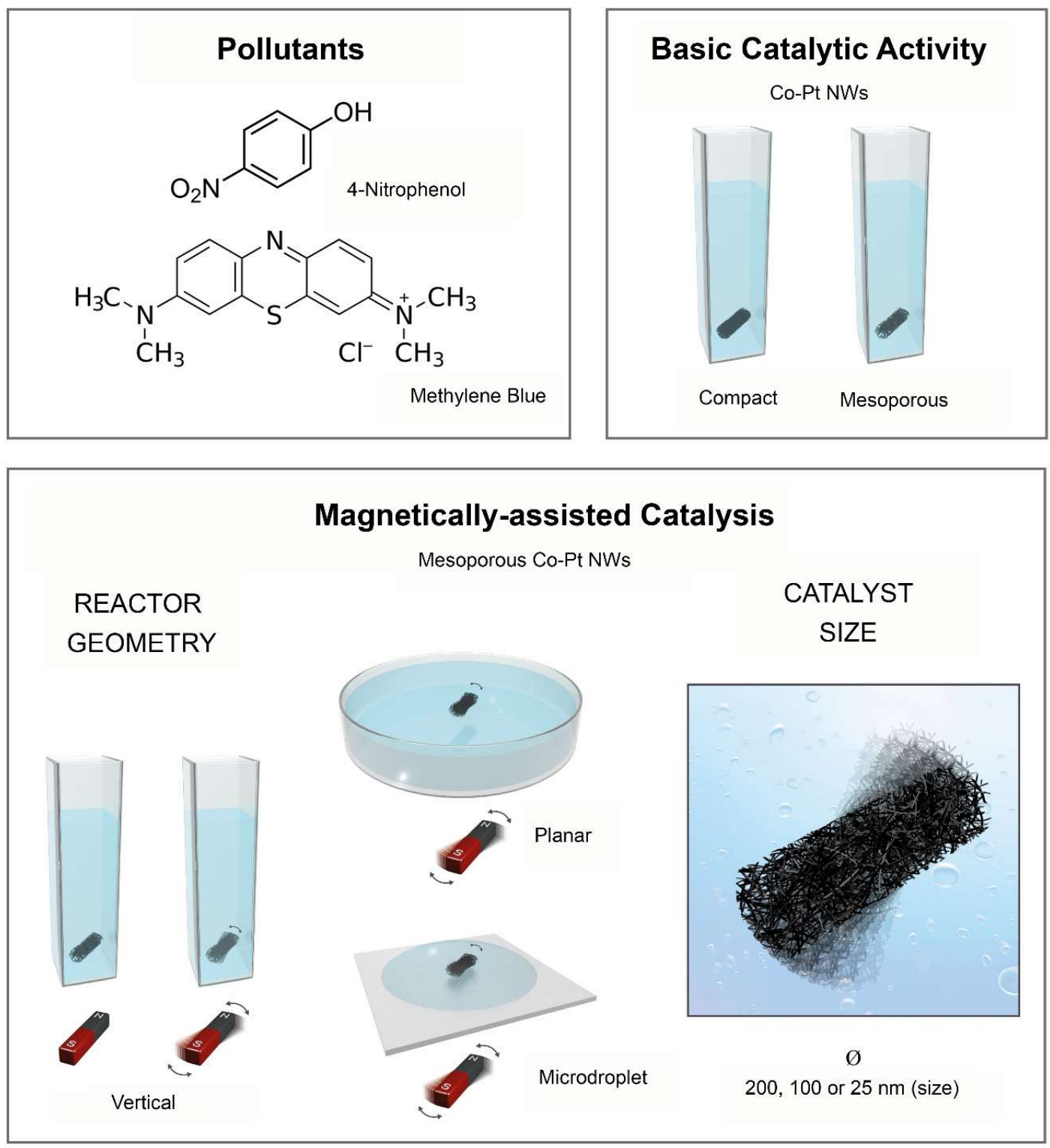

Figure 2: Scheme of the different reaction conditions.

Importantly, the effect of the field increases for higher rotating speeds. For example, the time for a full degradation of 4-nitrophenol and methylene blue is reduced by an excellent 2-fold factor when comparing the experiment in absence of magnetic field with that in which a $1200 \mathrm{rpm}$ rotating field is applied. In fact, the $k_{n o r}$ values for the mesoporous NWs for both types of reactions (Figure 3a and Table S2) are exceptionally high, outperforming all state-of-the-art catalysts proposed to date to degrade these pollutants (see Table S4). It is likely that the local magnetic field (and field gradients) promote a better 
local circulation of the liquid containing the pollutant, allowing it to easily reach the catalyst. However, as can be seen in the evolution of $k_{n o r}$ with rotating speed (Figure 3) there is a tendency towards saturation for the highest speeds. This is probably caused by the fact that for sufficiently high speeds the NWs will no longer be able to follow the field. If fact, for even higher speeds other effects, like the heating of the wires due to hysteresis losses, could lead to new consequences in the reaction $[47,80]$.

In an attempt to further enhance the catalytic activity, magnetic and mechanical stirring were combined. The experiment was carried out using mechanical stirring at $100 \mathrm{rpm}$ together with a rotating magnetic field at the same frequency (Figure S7 and Video S1-S2). However, surprisingly, although the combined approach resulted in a better performance than mechanical stirring alone, it was worse than pure magnetic stirring. This probably stems from the fact that mechanical stirring not only displaces the liquid but also the catalyst NWs. As the NWs are moved away from the bottom of the container by the mechanical stirring, the magnetic field they feel becomes considerably weaker, thus the advantageous effects of the magnetic field (local stirring and magnetic field gradient effects) are progressively lost.

In a more classical role of catalysts with magnetic materials, the recyclability of the nanowire catalysts was also evaluated. As can be seen in Figures S10-11, both compact and mesoporous NWs showed excellent stability during cycling tests, where no obvious decrease of activity even after eight cycles was observed.

\subsubsection{Role of the reaction geometry.}

The above experiments evidence the importance of the mass flow to improve the time needed to fully degrade the 4-nitrophenol and methylene blue pollutants. Moreover, it is clear that the optimum performance of the NWs is attained when they are close to the magnet. Thus, for an additional optimization of the magnetic actuation in the catalytic reaction, the role of the shape of the reaction vessel from vertical to planar geometry was evaluated using the $100 \mathrm{~nm}$ diameter wires. Two types of approaches were investigated (Figure 2): (i) microdroplets and (ii) a wide container with low height (with the same reaction volume as the vertical case). The former experiment is important for lab-in-achip and microfluidics type of applications, while the latter would be more relevant for large-scale applications like waterwaste remediation.

Due to their small size, the quantitative evolution of the reaction in the microdroplets is rather complex. Thus, to evaluate the performance of the mesoporous NWs in the microdroplets, the discoloration in the different configurations were compared (see Video S5-S6). Indeed, the degradation of 4-nitrophenol and methylene blue proceeds considerably faster in the microdroplets than in the conventional container 
under the same magnetic field conditions. This is in concordance with the results obtained with composite microstirrers, which were demonstrated to efficiently enhance the catalysis of diverse types of reactions in microdroplet conditions $[32,33]$.

Similar effects are obtained when the experiment is carried out in a macroscopic container. Remarkably, just by changing the geometry of the reaction container from "rectangular vertical" to "cylindrical planar" geometry (see Figure 2) and maintaining the same reaction volume and the same magnetic stirring conditions (100 rpm and $1200 \mathrm{rpm}$ ), the efficiency of the reactions almost doubles leading to $k_{\text {nor }}$ as high as $14058 \mathrm{~s}^{-1} \mathrm{~g}^{-1}$ and $14600 \mathrm{~s}^{-1} \mathrm{~g}^{-1}$ for 4-nitrophenol and methylene blue, respectively (see Figure 3b, Figure S12, Table S3 and Videos S7-S8). These results clearly highlight the importance of the geometry to optimize the role of the magnetic field.

\subsubsection{Role of the catalyst size.}

In a final attempt to further optimize the efficiency of the catalytic reactions we investigate the effect of the diameter of the mesoporous CoPt NWs. The idea of using different diameters is two-fold: (i) to assess the effect that the geometry of the NWs may have in the microstirring process and (ii) to evaluate the role of the surface area of the NWs, which increases as the diameter is decreased (Table S3).

The degradation of the water pollutants was carried out at $1200 \mathrm{rpm}$ both in vertical and planar containers. The results, shown in Figure 3c, Table S3 and Figure S13, unambiguously demonstrate that in all the conditions the narrower $25 \mathrm{~nm}$ wires have a significantly better performance for both types of reactions than the wider ones. The best performance is obtained for mesoporous $25 \mathrm{~nm}$ NWs at 1200 rpm in planar geometry, with $k_{n o r}=20667$ and $21750 \mathrm{~s}^{-1} \mathrm{~g}^{-1}$, for 4-nitrophenol and methylene blue, respectively.

Interestingly, when comparing the increase in surface area with the enhanced catalytic performance it is clear that apart from the surface area, the magnetic actuation also plays an important role in the catalytic activity. Namely, when decreasing the diameter from $200 \mathrm{~nm}$ to $25 \mathrm{~nm}$, the surface area only increases a factor $\operatorname{ECSA}(25 \mathrm{~nm}) / \operatorname{ECSA}(200 \mathrm{~nm})=1.56$, while the kinetic constant improves substantially more $k_{n o r}(25 \mathrm{~nm}) / k_{n o r}(200 \mathrm{~nm})=2.2$. 

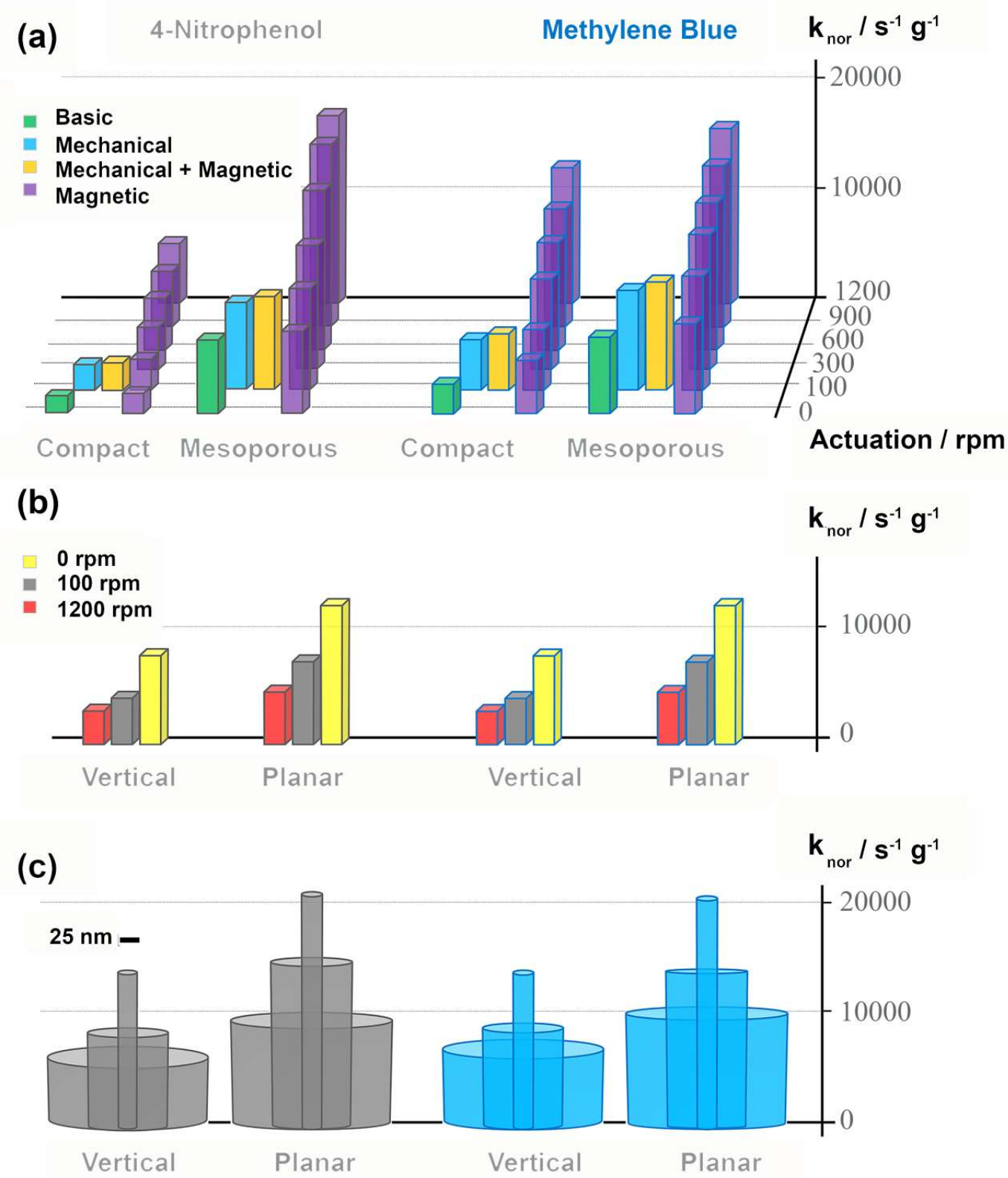

Figure 3: Values of the normalized rate constants, $k_{n o r}$, for the pollutants degradation. (a) Actuation type for CoPt $100 \mathrm{~nm}$ NWs. (b) Influence of the reactor geometry for CoPt $100 \mathrm{~nm} \mathrm{NWs}$ at different magnetic actuation (c) Influence of the catalyst diameter of CoPt NWs (200, 100 and $25 \mathrm{~nm}$ ) at 1200 rpm of magnetic actuation.

Remarkably, when comparing the somewhat standard procedure of $100 \mathrm{~nm}$ compact NWs with mechanical stirring in a vertical container with the novel approach of $25 \mathrm{~nm}$ mesoporous NWs with 1200 rpm magnetic microstirring in a planar container the gain in efficiency is simply impressive, 
reducing the degradation time by a factor 5.5 (Figure 4). This results in an improved mass normalized apparent kinetic constant of $k_{\text {nor }}=20667$ and $21750 \mathrm{~s}^{-1} \mathrm{~g}^{-1}$, which considerably exceeds all standard and advanced procedures for 4-nitrophenol and methylene blue degradation.
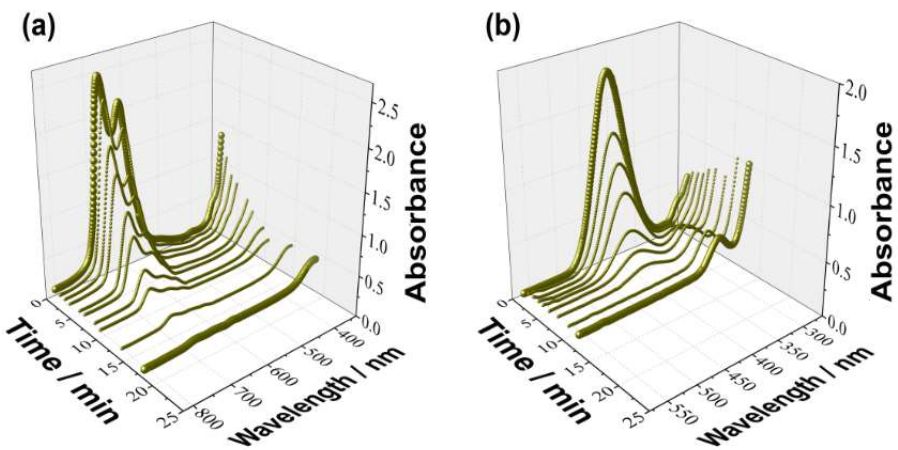

(c)

(d)

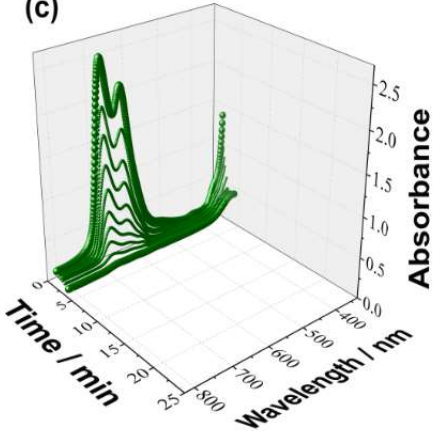

(e)
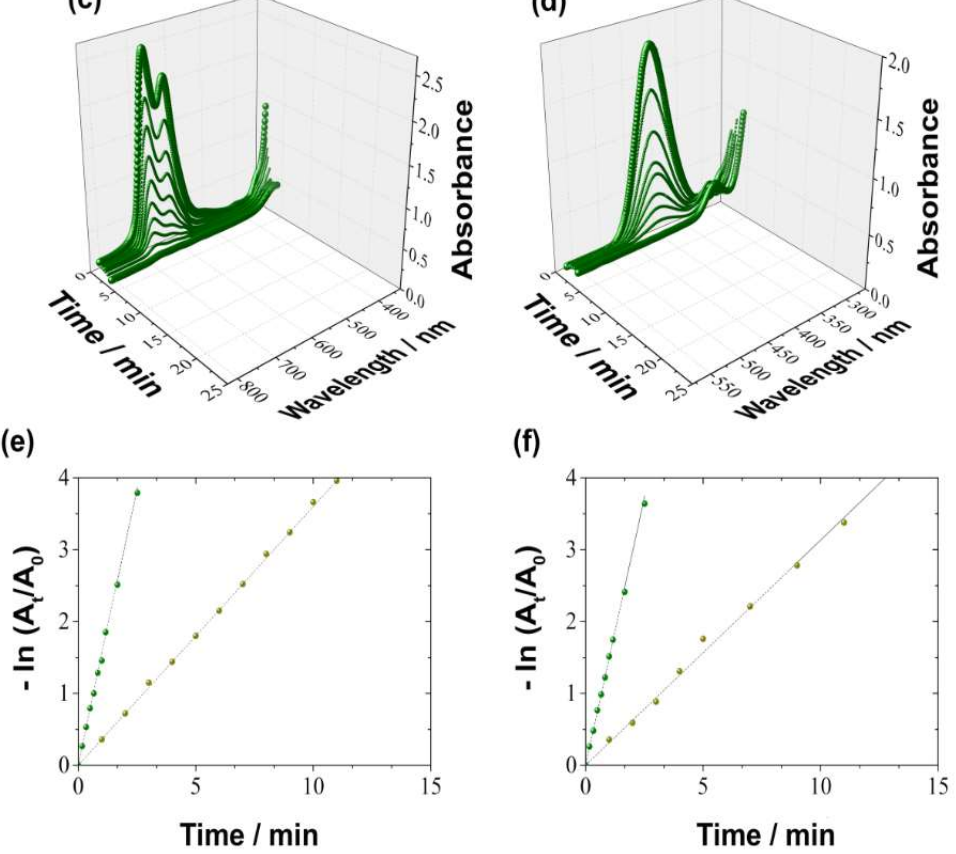

(f)

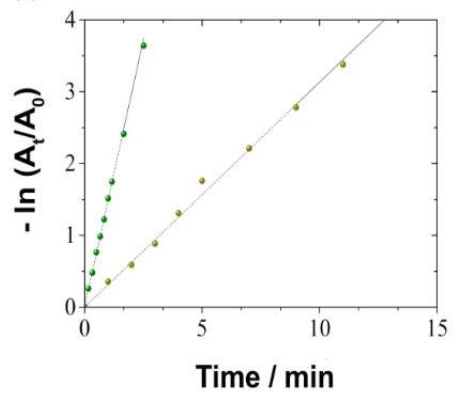

Figure 4: Time-dependent UV-Visible spectra of 4-nitrophenol (a, c) and methylene blue (b, d) catalysed reduction in (dark yellow) mechanical actuation (catalyst diameter: $100 \mathrm{~nm}$; actuation: 100 rpm; geometry: vertical) and (green) magnetic actuation (catalyst diameter: $100 \mathrm{~nm}$; actuation: 1200 rpm; geometry: planar) conditions, in which $12 \mu \mathrm{L}$ of a suspension of mesoporous Co-Pt NWs $(0.1$ $\left.\mathrm{mg} \mathrm{mL}^{-1}\right)$ were added. Plots of $-\ln \left(A_{t} / A_{0}\right)$ against reaction time for the catalyzed reduction of (e) 4nitrophenol or (f) methylene blue under (dark yellow) mechanical actuation (catalyst diameter: $100 \mathrm{~nm}$; actuation: $100 \mathrm{rpm}$; geometry: vertical) and (green) magnetic actuation (catalyst diameter: $100 \mathrm{~nm}$; actuation: $1200 \mathrm{rpm}$; geometry: planar) conditions, in which $12 \mu \mathrm{L}$ of a suspension of mesoporous $\mathrm{Co}-$ Pt NWs $\left(0.1 \mathrm{mg} \mathrm{mL}^{-1}\right)$ were added. 


\subsection{Hydrogen production}

It is well known that sodium borohydride $\left(\mathrm{NaBH}_{4}\right)$ is a preeminent candidate for pure hydrogen generation by means of its irreversible hydrolysis (Eq. 3), with the significant advantage that $50 \%$ of the produced hydrogen originates from water itself, since sodium borohydride is a water-splitting agent [81-84]. Importantly, the formation of hydrogen from borohydride decomposition produces pure $\mathrm{H}_{2}$ without carbon contaminations such as $\mathrm{CO}$ or $\mathrm{CO}_{2}$. Moreover, $\mathrm{NaBH}_{4}$ is stable, non-flammable, nontoxic and it is able to store hydrogen with a capacity of $10.8 \mathrm{wt}$ \%. [84-86]. Sodium metaborate $\left(\mathrm{NaBO}_{2}\right)$, which is formed simultaneously to hydrogen in the reaction described in Eq. 3, is also environmentally clean and it can actually be recycled by electrosynthesizing it back to sodium borohydride (Eq. 4) [81]:

$$
\mathrm{NaBO}_{2}+2 \mathrm{H}_{2} \mathrm{O} \rightarrow \mathrm{NaBH}_{4}+2 \mathrm{O}_{2} \text { (Eq. 4) }
$$

Hence, in these conditions, only water would be consumed for hydrogen production. Consequently, borohydride is a great candidate for direct fuel cells [87-89]. By extension, the development of competitive catalysts for this type of reaction is of major importance; especially using catalysts viable for industrial applications (i.e. low cost and good catalytic activity), since the non-catalysed hydrolysis is extremely slow (see Figure S14).

The magnetically-actuated catalysis for hydrogen production was determined by measuring the hydrogen generation yield as a function of time in both vertical $\left(\pi \times 7^{2} \times 7.0 \mathrm{~mm}^{3}\right)$ and planar $\left(\pi \times 12^{2}\right.$ x $2.4 \mathrm{~mm}^{3}$ ) reaction conditions using compact and mesoporous $25 \mathrm{~nm}$ NWs. Figure 5 and $\mathbf{S 1 5}$ and Table 2 show that the catalytic performance dramatically depends on three factors: (i) catalyst nature; (ii) reactor geometry; and (iii) use or not of magnetic actuation. In agreement with the pollutant degradation reactions the combination of mesoporosity-planar geometry and magnetic actuation renders the best hydrogen generation activity, leading to remarkable $25.0 \mathrm{~L} \mathrm{H}_{2} \mathrm{~g}^{-1} \mathrm{~min}^{-1}$. In fact, in these conditions the reaction reaches its maximum yield in less than $1000 \mathrm{~s}$ (Figure 5 and S15 and Table 2). Hence, the three factors together play a synergetic role in optimizing the kinetics of heterogeneous catalysis. For example, compared to the reaction using magnetically actuated compact nanowires in vertical geometry, an impressive 312x improvement is obtained (compare entries $i$ and vi Table 2). Importantly, the maximum values of hydrogen generation rate were obtained by a differential procedure and correspond to the instantaneous rate at $\mathrm{t}=0 \mathrm{~s}$. However, these values do not necessarily match exactly the maximum reaction rate for mesoporous NWs as a consequence of the pore diffusion resistance $[60,61]$. Despite this limitation, the values for the hydrogen generation activity are far better than in many other catalysts and are actually comparable to the more competitive state-of-the-art solid catalysts based on noble metals [47, 81-97] (Table S4). In addition, this approach offers the relevant 
advantage of reducing the Pt content (i.e., cost-effectiveness) and the important benefits from the magnetic behaviour of the catalysts, i.e., easy manipulation, recyclability and improved catalytic performance. Nevertheless, it should be emphasized that the hydrogen generation activity values in Table 2 are based on the use of only $4.2 \mathrm{mM}$ of $\mathrm{NaBH}_{4}$, while most of the reactions reported in Table S4 use between 50 and 1000 times more $\mathrm{NaBH}_{4}$. Since the hydrolysis of $\mathrm{NaBH}_{4}$ cannot be clearly considered a zero-order reaction $[98,99]$, the catalytic activity should be affected by the amount of $\mathrm{NaBH}_{4}$. Taking this fact into account, using magnetically actuated mesoporous CoPt nanowires in planar geometry should far surpass all current hydrogen generation approaches based on $\mathrm{NaBH}_{4}$.

\begin{tabular}{|c|c|c|c|c|c|c|}
\hline $\begin{array}{c}\text { Entr } \\
\mathbf{y}\end{array}$ & Catalyst & $\begin{array}{l}\text { Reactor } \\
\text { geometry }\end{array}$ & $\begin{array}{c}\text { Magnetic } \\
\text { Actuation / } \\
\text { rpm }\end{array}$ & $\begin{array}{c}\text { Hydrogen } \\
\text { generation yield } \\
(1200 \text { s }) / \%\end{array}$ & $\begin{array}{c}\text { Activity / L } \\
\mathbf{H}_{2} \mathrm{gcat}^{-1} \mathrm{~min}^{-} \\
1\end{array}$ & $\begin{array}{c}\text { Activity } \\
\text { Enhance } \\
\text { ment }^{\text {a }}\end{array}$ \\
\hline $\mathrm{i}$ & $\begin{array}{c}\text { Compact } \\
\text { NWs }\end{array}$ & Vertical & 1200 & 1.0 & 0.08 & 1 \\
\hline ii & $\begin{array}{c}\text { Compact } \\
\text { NWs }\end{array}$ & Planar & 0 & 4.6 & 0.25 & 3.1 \\
\hline iii & $\begin{array}{c}\text { Compact } \\
\text { NWs }\end{array}$ & Planar & 1200 & 24.1 & 1.50 & 18.8 \\
\hline iv & $\begin{array}{c}\text { Mesoporous } \\
\text { NWs }\end{array}$ & Vertical & 1200 & 41.8 & 3.02 & 37.8 \\
\hline $\mathrm{v}$ & $\begin{array}{c}\text { Mesoporous } \\
\text { NWs }\end{array}$ & Planar & 0 & 67.2 & 10.00 & 125 \\
\hline vi & $\begin{array}{c}\text { Mesoporous } \\
\text { NWs }\end{array}$ & Planar & 1200 & 100.0 & 25.00 & 312.5 \\
\hline
\end{tabular}

Table 2: Comparison of catalytic conditions and hydrogen generation performance of compact and mesoporous $25 \mathrm{~nm}$ NWs in vertical and planar reaction geometry and silent and magnetic actuated heterogeneous catalysis. All reactions were performed using $1 \mathrm{~mL}$ of $4.2 \mathrm{mM} \mathrm{NaBH}_{4}(\mathrm{pH} 13)$ and 24 $\mu \mathrm{L}$ of a catalyst ink $\left(0.1 \mathrm{mg} \mathrm{mL}^{-1}\right)$ at $25^{\circ} \mathrm{C}$.

${ }^{a}$ Relative to experiment i. 


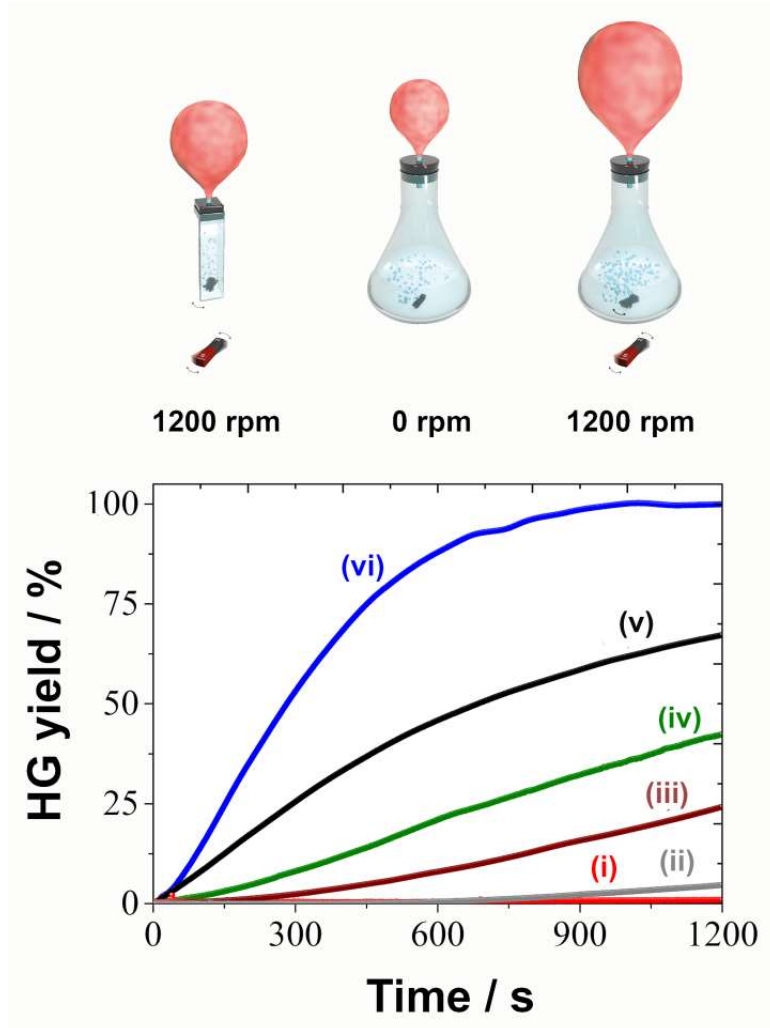

Figure 5: Hydrogen generation ( $\mathrm{HG})$ yield as a function of reaction time for compact (i, ii, iii) mesoporous (iv, v, vi) $25 \mathrm{~nm}$ NWs in planar (ii, iii, v, vi) or vertical (i, iv) reaction geometry and silent (ii and v) or magnetic actuation (i, iii, iv, and vi) conditions

\section{Conclusions}

Summarizing, we have evaluated magnetic actuation of entirely magnetic NWs as a novel procedure to enhance the catalytic activity for two significant reactions in environmental and energy fields: the reduction reaction of 4-nitrophenol and methylene blue water pollutants with borohydride and purehydrogen production by means of borohydride decomposition. These NWs have a huge catalytically active surface and are easily manipulated (i.e., remote stirring) using magnetic field, combined in a simple, inexpensive, single material (in contrast to most previous multicomponent complex advanced magnetic catalysts). The results show that there are several aspects which need to be adjusted for optimal performance: (i) mesoporous NWs are much more effective than compact ones; (ii) high-speed (1200 rpm) magnetic actuation is shown to be far more effective than mechanical stirring in speeding the 
degradation process; (iii) planar geometry is better than vertical one; and (iv) narrow NWs (25 nm) evidence a considerably better catalytic performance than wider ones $(200 \mathrm{~nm})$ wires. In fact, $25 \mathrm{~nm}$ mesoporous NWs with $1200 \mathrm{rpm}$ magnetic microstirring in a planar container have an excellent degradation activity with $k_{n o r}=20667$ and $21750 \mathrm{~s}^{-1} \mathrm{~g}^{-1}$, for 4-nitrophenol and methylene blue, respectively, and a very effective room temperature rate constant of $25.0 \mathrm{~L} \mathrm{H}_{2} \mathrm{~g}^{-1} \mathrm{~min}^{-1}$ for hydrogen production. These outstanding performances demonstrate that magnetic actuation (magnetic field induced convection and remote magnetic microstirring) of purely magnetic narrow mesoporous $N W S$ is an efficient way to greatly enhance the catalytic efficiency in different reactions of heterogeneous catalysis, including energy production by fuel cells. Interestingly, the advantages of using $\mathrm{CoPt}$ mesoporous NWs as an entirely magnetic catalyst are numerous: (i) it results in magnetic field-induced convection, (ii) it can be used as a remote microstirring device, (iii) it allows easy and efficient recyclability, (iv) it is very robust, (v) it benefits from a cost-effective and easily scalable synthesis that does not require of hybrid multi-component catalysts and (vi) it reduces the cost of materials since the amount of Pt precious metal is reduced. Hence, the high efficiency of magnetic actuation together with the simplicity and cost-effective synthesis approach and the efficient recyclability of the magnetic mesoporous NW catalysts make this approach very appealing to commercialize new viable alternatives for ecological decontamination and clean energy production.

\section{Acknowledgements}

This work was supported by the EU ERDF (FEDER) fund and the Spanish Government grants TEC2014-51940-C2-2-R and MAT2014-57960-C3-1-R from Ministerio de Economía $y$ Competitividad (MINECO) -the latter cofinanced by FEDER. Partial funding from the European Research Council (Consolidator Grant, project n. 648454, SPIN-PORICS) and the Generalitat de Catalunya (2014-SGR-1015 project) is acknowledged. The authors thank the CCiT-UB for the use of their equipment and A. Llobet for the hydrogen evolution experiments, funded by MINECO and FEDER (CTQ-2016-80058-R, SEV-2013-0319, and CTQ-2014-52974-REDC) and EU COST actions CM1202 and CM1205. ICN2 acknowledges support from the Severo Ochoa Program (MINECO, Grant SEV-2013-0295). 


\section{References}

1. S. Hu, M. R. Shaner, J.A. Beardslee, M. Lichterman, B. S. Brunschwig, N. S. Lewis, Amorphous $\mathrm{TiO}_{2}$ coatings stabilize $\mathrm{Si}, \mathrm{GaAs}$, and $\mathrm{GaP}$ photoanodes for efficient water oxidation, Science 344 (2014) 1005-1009.

2. S. Bag, A.F. Gaudette, M.E. Bussell, M.G. Kanatzidis, Spongy chalcogels of non-platinum metals act as effective hydrodesulfurization catalysts, Nat. Chem. 1(2009) 217-224.

3. J.K. Nørskov, T. Bligaard, J. Rossmeis, C.H. Christensen, Towards the computational design of solid catalysts, Nat. Chem. 1 (2009) 37-46.

4. R. Saravanan, V.K. Gupta, V. Narayanan, A. Stephen, Comparative study on photocatalytic activity of ZnO prepared by different methods, J. Mol. Liq. 181 (2013) 133-141.

5. R. Saravanan, V.K. Gupta, V. Narayanan, A. Stephen, Visible light degradation of textile effluent

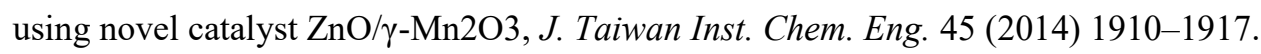

6. V.K. Gupta, R. Jain, A. Mittal, T.A. Saleh, A. Nayak, S. Agarwal, S. Sikarwar, Photo-catalytic degradation of toxic dye amaranth on TiO2/UV in aqueous suspensions, Mater. Sci. Eng. C. 32 (2012) 12-17.

7. F. Nakajima, Air pollution control with catalysis - past, present and future -. Catal. Today 10 (1991) 1-20.

8. P.A. Pekakis, N.P. Xekoukoulotakis, D. Mantzavinos, Treatment of textile dyehouse wastewater by $\mathrm{TiO}_{2}$ photocatalysis. Water Res. 40 (2006) 1276-1286.

9. F. Mushtag, M. Guerrero, M. Selmon-Sakar, M. Hoop, A. Lindo, J. Sort, X. Chen, B.J. Nelson, E. Pellicer, S. Pané, Magnetically driven $\mathrm{Bi}_{2} \mathrm{O}_{3} / \mathrm{BiOCl}^{-}$based hybrid microrobots for photocatalytic water remediation, J. Mater. Chem. A 3 (2015) 23670-23683.

10. I. Galvano-Escobal, S. Suriñach, M.D. Baró, S. Pané, J. Sort, E. Pellicer, Electrodeposition of sizeable and compositionally tunable rhodium-iron nanoparticles and their activity toward hydrogen evolution reaction, Electrochim. Acta 194 (2016) 263-275.

11. V.K. Gupta, R. Jain, A. Nayak, S. Agarwal, M. Shrivastava, Removal of the hazardous dyeTartrazine by photodegradation on titanium dioxide surface, Mater. Sci. Eng. C. 31 (2011) 10621067.

12. T.A. Saleh, V.K. Gupta, Photo-catalyzed degradation of hazardous dye methyl orange by use of a composite catalyst consisting of multi-walled carbon nanotubes and titanium dioxide, J. Colloid Interface Sci. 371 (2012) 101-106.

13. A.C. Aragonès, N.L. Haworth, N. Darwish, S. Ciampi, N.J. Bloomfield, G.G. Wallace, I. DiezPerez, M.L. Coote, Electrostatic catalysis of a Diels-Alder reaction, Nature 531 (2016) 88-91.

14. J.-T. Li, J.-F. Han, J.-H. Yang, T.-S. Li, An efficient synthesis of 3,4-dihydropyrimidin-2-ones catalysed by $\mathrm{NH}_{2} \mathrm{SO}_{3} \mathrm{H}$ under ultrasound irradiation. Ultrason. Sonochem. 10 (2003) 119-122. 
15. X. Chen, L. Liu, P.Y. Yu, S.S. Mao, Increasing solar absorption for photocatalysis with black hydrogenated titanium dioxide nanocrystals, Science 331 (2011) 746-750.

16. T. Noël, J.R. Naber, R.L. Hartman, J.P. McMullen, K.F. Jensen, S.L. Buchwald, Palladiumcatalyzed amination reactions in flow: overcoming the challenges of clogging via acoustic irradiation, Chem. Sci. 2 (2011) 287-290.

17. R. Saravanan, M. Mansoob Khan, V.K. Gupta, E. Mosquera, F. Gracia, V. Narayanan, A. Stephen, $\mathrm{ZnO} / \mathrm{Ag} / \mathrm{CdO}$ nanocomposite for visible light-induced photocatalytic degradation of industrial textile effluents, J. Colloid Interface Sci. 452 (2015) 126-133.

18. R. Saravanan, V.K. Gupta, T. Prakash, V. Narayanan, A. Stephen, Synthesis, characterization and photocatalytic activity of novel $\mathrm{Hg}$ doped $\mathrm{ZnO}$ nanorods prepared by thermal decomposition method, J. Mol. Liq. 178 (2013) 88-93.

19. T.A. Saleh, V.K. Gupta, Functionalization of tungsten oxide into MWCNT and its application for sunlight-induced degradation of rhodamine B, J. Colloid Interface Sci. 362 (2011) 337-344.

20. R. Saravanan, E. Sacari, F. Garcia, M.M. Khan, E. Mosquera, V. K. Gupta, Conducting PANI simulated $\mathrm{ZnO}$ system for visible light photocatalytic degradation of colored dyes, J. Mol. Liq. 221 (2016) 1029-1033.

21. S. Rajendran, M.M. Khan, F. Gracia, J. Qin, V.K. Gupta, S. Arumainathan, $\mathrm{Ce}^{3+}$-ion-induced visible-light photocatalytic degradation and electrochemical activity of $\mathrm{ZnO} / \mathrm{CeO}_{2}$ nanocomposite, Nat. Publ. Gr. (2016) 1-11.

22. R. Saravanan, V.K. Gupta, E. Mosquera, F. Gracia, V. Narayanan, A. Stephen, Visible light induced degradation of methyl orange using $\beta-\mathrm{Ag}_{0.333} \mathrm{~V}_{2} \mathrm{O}_{5}$ nanorod catalysts by facile thermal decomposition method, J. Saudi Chem. Soc. 19 (2015) 521-527.

23. D. Astruc, F. Lu, J.R. Aranzaes, Nanoparticles as recyclable catalysts: the frontier between homogenous and heterogeneous catalysis, Angew. Chem. Int. Edit. 44 (2005) 7852-7872.

24. B. Hinnemann, P.G. Moses, J. Bonde, K.P. Jorgensen, J.H. Nielsen, S. Horch, I. Chorkendorff, J.K. Norskov, Biomimetic hydrogen evolution: $\mathrm{MoS}_{2}$ nanoparticles as catalyst for hydrogen evolution. J. Am. Chem. Soc. 127 (2005) 5308-5309.

25. R. Saravanan, N. Karthikeyan, V.K. Gupta, E. Thirumal, P. Thangadurai, V. Narayanan, A. Stephen, $\mathrm{ZnO} / \mathrm{Ag}$ nanocomposite: An efficient catalyst for degradation studies of textile effluents under visible light, Mater. Sci. Eng. C. 33 (2013) 2235-2244.

26. R. Saravanan, S. Joicy, V.K. Gupta, V. Narayanan, A. Stephen, Visible light induced degradation of methylene blue using $\mathrm{CeO}_{2} / \mathrm{V}_{2} \mathrm{O}_{5}$ and $\mathrm{CeO}_{2} / \mathrm{CuO}$ catalysts, Mater. Sci. Eng. C. 33 (2013) $4725-4731$. 
27. R. Saravanan, S. Karthikeyan, V.K. Gupta, G. Sekaran, V. Narayanan, A. Stephen, Enhanced photocatalytic activity of $\mathrm{ZnO} / \mathrm{CuO}$ nanocomposite for the degradation of textile dye on visible light illumination, Mater. Sci. Eng. C. 33 (2013) 91-98.

28. R. Saravanan, E. Thirumal, V.K. Gupta, V. Narayanan, A. Stephen, The photocatalytic activity of $\mathrm{ZnO}$ prepared by simple thermal decomposition method at various temperatures, J. Mol. Liq. 177 (2013) 394-401.

29. R. Saravanan, V.K. Gupta, E. Mosquera, F. Gracia, Preparation and characterization of $\mathrm{V}_{2} \mathrm{O}_{5} / \mathrm{ZnO}$ nanocomposite system for photocatalytic application, J. Mol. Liq. 198 (2014) 409412.

30. A. Taguchi, F Schüth, Ordered mesoporous materials in catalysis. Micropor. Mesopor. Mat. 77 (2005) 1-45.

31. A. Serrà, E. Gómez, E. Vallés, Novel electrodeposition media to synthesize CoNi-Pt core@shell stable mesoporous nanorods with very high active surface for methanol electro-oxidation. Electrochim. Acta 174 (2015) 630-639.

32. S. Yang, C. Cao, Y. Sun, P. Huang, F. Wei, S. Weiguo, Nanoscale magnetic stirrers bar for heterogeneous catalysis in microscopic systems. Angew. Chem. Int. Edit. 54 (2015) 2661-2664.

33. S.L. Biswal, A.P. Gast, Micromixing with linked chains of paramagnetic particles. Anal. Chem. 76 (2004) 6648-6455.

34. I. Petosuis, E. Homburg, R. Derks and A. Dietzel, Transient behaviour of magnetic micro-bead chains rotating in a fluid by external. Lab. Chip 7 (2007) 1746-1751.

35. G. Hinds, J.M.D. Coey, M.E.G. Lyons, Influence of magnetic forces on electrochemical mass transport. Electrochem. Commun. 3 (2011) 215-218.

36. L.M.A. Monzon, J.M.D. Coey, Magnetic fields in electrochemistry: The Lorentz force. A minireview. Electrochem. Commun. 42 (2014) 38-41.

37. L.M.A. Monzon, L.M.A. Coey, Magnetic fields in electrochemistry: The Kelvin force. A minireview. Electrochem. Commun. 42 (2014) 42-45.

38. X. Xiong, Y. Sun, B. Sun, W. Song, J. Sun, N. Gao, J. Qiao, X. Guan, Enhancement of the advanced Fenton process by weak magnetic field for the degradation of 4-nitrophenol. RSC Adv. 5 (2015) 13357-13365.

39. J. Sá, J. Szlachetko, M. Sikora, M. Kavcic, O.V. Safonovam, M. Nachtegaal, Magnetic manipulation of molecules on non-magnetic catalytic surface. Nanoscale 5 (2013) 8462-8465.

40. D. Wang, D. Astruc, Fast-growing field of magnetically recyclable nanocatalysts. Chem. Rev. 114 (2014) 6949-6985.

41. A. Serrà, E. Gómez, E. Vallés, Facile electrochemical synthesis, using microemulsions with ionic liquid, of highly mesoporous CoPt nanorods with enhanced electrocatalytic performance for clean energy. Int. J. Hydrogen. Energy 40 (2015) 8062-8070. 
42. J. Xia, Y. Fu, G. He, X. Sun, X. Wang, Core-shell-like Ni-Pd nanoparticles supported on carbon black as a magnetically separable catalyst for green Suzuki-Miyaura coupling reactions. Appl. Catal. B-Environ. 200 (2017) 39-46.

43. S.K. Srivastava, M. Guix, O.G. Schmidt, Wastewater mediated activation of Micromotors for efficient water cleaning. Nano Lett. 16 (2015) 817-821.

44. D. Vilela, J. Parmar, Y. Zeng, Y. Zhao, S. Sánchez, Graphene-based microrobots for toxic heavy metal removal and recovery from water. Nano Lett. 16 (2015) 2860-2866.

45. W.H. Chong, L.K. Chin, R.L. Tan, H. Wang, A.Q. Liu, H. Chen, Stirring in suspension: nanometer-sized magnetic stir bars. Angew. Chem. Ed. Int. 52 (2013) 8570-8573.

46. S. Yang, C. Cao, L. Peng, P. Huang, Y. Sun, F. Wei, W. Song, Spindle-shaped nanoscale yolk/shell magnetic stirring bars for heterogeneous catalysis in macro- and microscopic systems. Chem. Commun. 52 (2016) 1575-1578.

47. Y. Liu, J. Zhang, X. Zhang, B. Li, X. Wang, H. Cao, D. Wei, Z. Zhou, A.K. Cheetham, Magnetic catalysts as nanoactuators to achieve simultaneous momentum-transfer and continuous-flow hydrogen production. J. Mater. Chem. A 4 (2016) 4280-4287.

48. S. Yamakawa, R. Asahi, T. Koyama, Surface segregations in platinum-based alloy nanoparticles. Surf. Sci. 622 (2014) 65-70.

49. O. Song-Il, J.-M. Yan, H.-L. Wang, Z.-L. Wang, Q. Jiang, High catalytic kinetic performance of amorphous CoPt NPs induced on $\mathrm{CeO}_{\mathrm{x}}$ for $\mathrm{H}_{2}$ generation from hydrous hydrazine, Int. J. Hydrogen. Energ. 39 (2014) 3755-3761.

50. J. Greeley, I.E.L. Stephens, A.S. Bondarenko, T.P. Johansson, H.A. Hansen, T.F. Jaramillo, J. Rossmeisl, I. Chorkendorff, J.K. Nørskov, Alloys of platinum and early transition metals as oxygen reduction electrocatalysts. Nat. Chem. 1 (2009) 552-558.

51. B. Lim, M. Jiang, P.H.C. Camargo, E.C. Cho, J. Tao, X. Lu, Y. Zhu,Y. Xia, Pd-Pt bimetallic nanodendrites with high activity for oxygen reduction. Science 324 (2009) 1302-1305.

52. B.A. Kakade, H. Wang, T. Tamaki, H. Ohashi, T. Yamaguchi, Enhanced oxygen reduction reaction by bimetallic CoPt and PdPt nanocrystals, RSC Adv. 3 (2013) 10487-10496.

53. B.A. Kakade, T. Tamaki, H. Ohashi and T. Yamaguchi, Highly active bimetallic PdPt and CoPt nanocrystals for methanol electro-oxidation, J. Phys. Chem. C 116 (2012) 7464-7470.

54. A. Serrà, E. Gómez, I.V. Golosovsky, J. Nogués, E. Vallés, Effective ionic-liquid microemulsions based electrodeposition of mesoporous Co-Pt films for methanol oxidation catalysis in alkaline media. J. Mater. Chem. A 4 (2016) 7805-7814.

55. Q.-S. Chen, S.-G. Sun, Z.-Y. Zhou, Y.-X. Chen, S.-B. Deng, CoPt nanoparticles and their catalytic properties in electrooxidation of $\mathrm{CO}$ and $\mathrm{CH}_{3} \mathrm{OH}$ studied by in situ FTIRS. Phys. Chem. Chem. Phys. 10 (2008) 3645-3654. 
56. A. Serrà, E. Gómez, M. Montiel, E. Vallés, Effective new method for synthesising $\mathrm{Pt}$ and $\mathrm{CoPt}_{3}$ mesoporous nanorods. New catalysts for ethanol electro-oxidation in alkaline medium. RSC Adv. 6 (2016) 47931-47939.

57. A. Serrà, N. Gimeno, E. Gómez, M. Mora, M. Ll. Sagristá, E. Vallés, Magnetic mesoporous nanocarriers for drug delivery with improved therapeutic efficacy, Adv. Funct. Mater. 26(2016) 6601-6611.

58. L. Vieux-Rochaz, C. Dieppedale, B. Desloges, D. Gamet, C. Barragatti, H. Rostaing, J. MeunierCarus, Electrodeposition of hard magnetic CoPtP material and integration into magnetic MEMS, J. Micromechanics Microengineering. 16 (2005) 219-224.

59. A. Serrà, X. Alcobé, J. Sort, J. Nogués, E. Vallés, Highly efficient electrochemical and chemical hydrogenation of 4-nitrophenol using recyclable narrow mesoporous magnetic CoPt nanowires, J. Mater. Chem. A. 4 (2016) 15676-15687.

60. Y. J. Zhang, Y. T. Yang, Y. Liu, Y. X. Wang, L. L. Yang, M. B. Wei, H. G. Fan, H. J. Zhai, X. Y. Liu, Y. Q. Liu, N. N. Yang, Y. H. Wu, J. H. Yang, A novel approach to the synthesis of CoPt magnetic nanoparticles, J. Phys. D: Appl. Phys. 44 (2011) 295003-29508.

61. V.K. Gupta, A. Nayak, Cadmium removal and recovery from aqueous solutions by novel adsorbents prepared from orange peel and $\mathrm{Fe}_{2} \mathrm{O}_{3}$ nanoparticles, Chem. Eng. J. 180 (2012) 81-90.

62. A.K. Jain, V.K. Gupta, A. Bhatnagar-Suhas, A Comparative Study of Adsorbents Prepared from Industrial Wastes for Removal of Dyes, Sep. Sci. Technol. 38 (2003) 463-481.

63. V.K. Gupta, R. Kumar, A. Nayak, T.A. Saleh, M.A. Barakat, Adsorptive removal of dyes from aqueous solution onto carbon nanotubes: A review, Adv. Colloid Interface Sci. 193-194 (2013) 24-34.

64. V.K. Gupta, T.A. Saleh, Sorption of pollutants by porous carbon, carbon nanotubes and fullereneAn overview, Environ. Sci. Pollut. Res. 20 (2013) 2828-2843.

65. N. Mohammadi, H. Khani, V.K. Gupta, E. Amereh, S. Agarwal, Adsorption process of methyl orange dye onto mesoporous carbon material-kinetic and thermodynamic studies, J. Colloid Interface Sci. 362 (2011) 457-462.

66. T.A. Saleh, V.K. Gupta, Processing methods, characteristics and adsorption behavior of tire derived carbons: A review, Adv. Colloid Interface Sci. 211 (2014) 93-101.

67. A. Mittal, J. Mittal, A. Malviya, D. Kaur, V.K. Gupta, Decoloration treatment of a hazardous triarylmethane dye, Light Green SF (Yellowish) by waste material adsorbents, J. Colloid Interface Sci. 342 (2010) 518-527.

68. A. Mittal, D. Kaur, A. Malviya, J. Mittal, V.K. Gupta, Adsorption studies on the removal of coloring agent phenol red from wastewater using waste materials as adsorbents, J. Colloid Interface Sci. 337 (2009) 345-354. 
69. A. Mittal, J. Mittal, A. Malviya, V.K. Gupta, Adsorptive removal of hazardous anionic dye "Congo red" from wastewater using waste materials and recovery by desorption, J. Colloid Interface Sci. 340 (2009) 16-26.

70. V.K. Gupta, I. Ali, T. a. Saleh, A. Nayak, S. Agarwal, Chemical treatment technologies for wastewater recycling—an overview, RSC Adv. 2 (2012) 6380.

71. G. Huang, L. Yang, X. Ma, J. Jiang, S.H. Yu, H.-L. Jiang. Metal-organic framework-templated porous carbon for highly efficient catalysis: the critical role of pyrrolic nitrogen species. Chem. Eur. J. 22 (2016) 3470-3477.

72. J.-J. Lv, A.-J. Wang, X. Ma, R.-Y. Xiang, J.-R. Chen, and J.-J. Feng, One-pot synthesis of porous Pt-Au nanodendrites supported on reduced graphene oxide nanosheets toward catalytic activity reduction of 4-nitrophenol. J. Mater. Chem. A 3 (2015) 290-296.

73. W. Ye, J. Yu, Y. Zhou, D. Wang, C. Wang, D. Xue, Green synthesis of Pt-Au dendrimer-like nanoparticles supported on polydopamine-functionalized graphene and their high performance toward 4-nitrophenol reduction. Appl. Catal. B-Environ. 181 (2016) 371-378.

74. Y.-Y. Shen, Y. Sun, L.-N. Zhou, Y.-J. Li, E.S. Yeung, Synthesis of ultrathin PtPdBi nanowire and its enhanced catalytic activity towards p-nitrophenol reduction. J. Matter. Chem. A 2 (2014) 2977-2984.

75. G. Cui, Z. Sun, H. Li, Z. Liu, Y. Tian, S. Yan, Synthesis and characterization of magnetic elongated hollow mesoporous silica nanocapsules with silver nanoparticles. J. Mater. Chem. A 4 (2016) 1771-1783.

76. S.K. Ghosh, M. Mandal, S. Kundu, S. Nath, T. Pal, Bimetallic Pt-Ni nanoparticles can catalyse reduction of aromatic nitro compounds by sodium borohydride in aqueous solution. Appl. Catal. A 268 (2004) 61-66.

77. V.K. Gupta, N. Atar, M.L. Yola, Z. Üstündag, L.A. Uzun, A novel magnetic Fe@Au core-shell nanoparticles anchored graphene oxide recyclable nanocatalysts for the reduction of nitrophenol compounds. Water Res. 48 (2014) 210-217.

78. M. Zhu, C. Wang, D. Meng, G. Diao, G. In situ synthesis of silver nanostructures on magnetic $\mathrm{Fe}_{3} \mathrm{O}_{4} @ \mathrm{C}$ core-shell nanocomposites and their application in catalytic reduction reactions. $J$. Mater. Chem. A 1 (2013) 2118-2125.

79. Y. Xie, B. Yan, H. Xu, J. Chen, Q. Liu, Y. Deng, H. Zeng, Highly regenerable Mussel-inspired $\mathrm{Fe}_{3} \mathrm{O}_{4} @$ polydopamine-Ag core-shell microspheres as catalyst and adsorbent for methylene blue removal. ACS Appl. Mater. Interfaces 6 (2014) 8845-8852.

80. L. Gao, C. Wang, R. Li, Q. Chen, The effect of external magnetic fields on the catalytic activity of Pd nanoparticles in Suzuki cross-coupling reactions. Nanoscale 8 (2016) 8355-8362. 
81. D. M. F. Santos, C. A. C. Sequeira, Sodium borohydride as a fuel for the future, Renew. Sust. Energ. Rev. 15 (2011) 3980-4001.

82. R. Retnamma, A. Q. Novais, C.M. Rangel, Kinetics of hydrolysis of sodium borohydride for hydrogen production in fuel cell applications: a review, Int. J. Hydrogen. Energ. 36 (2011) 97729790.

83. S. Eugénio, U. B. Demirci, T. M. Silva, M. J. Carmezim, M. F. Montemor, Copper-cobalt foams as active and stable catalysts for hydrogen release by hydrolysis of sodium borohydride, Int. $J$. Hydrogen. Energ. 41 (2016) 8438-8448.

84. Y. Huang, K. Wang, L. Cui, W. Zhu, A. M. Asiri, X. Sun. Effective hydrolysis of sodium borohydride driven by self-supported cobalt oxide nanorod array for on-demand hydrogen generation, Catal. Commun. 87 (2016) 94-97.

85. A. Chinappan, R. Appiah-Ntiamoah, W.-J. Chung, H. Kim, Ionic liquid functionalized graphene oxide decorated with copper oxide nanostructures towards $\mathrm{H}_{2}$ generation from sodium, Int. J. Hydrogen. Energ. 41 (2016) 14491-14497.

86. S. Gupta, N. Patel, R. Fernandes, D.C: Kothari, A. Mitoello, Mesoporous Co-B nanocatalyst for efficient hydrogen production by hydrolysis of sodium borohydride, Int. J.Hydrogen Energ. 38 (2013) 14685-14692.

87. Y. Wang, P. He, H. Zhou, A novel direct borohydride fuel cell using an acid-alkaline hybrid electrolyte, Energy Environ. Sci. 3 (2010) 1515-1518.

88. U. B. Demirci, P. Miele, Sodium borohydride versus ammonia borane, in hydrogen storage and direct fuel cell applications, Energy Environ. Sci., 2 (2009) 627-637.

89. Y. Shang, R. Chen, Semiempirical hydrogen generation model using concentrated sodium borohydride solution, Energy Fuels 20 (2006) 2149-2154.

90. Y. Liang, P. Wang, H.-B. Dai, Hydrogen bubbles dynamic template preparation of a porous Fe$\mathrm{Co}-\mathrm{B} / \mathrm{Ni}$ foam catalyst for hydrogen generation from hydrolysis of alkaline sodium borohydride solution, J. Alloy. Compd. 491 (2010) 359-365.

91. Y. Bai, C. Wu, F. Wu, B. Yi, Carbon-supported platinum catalysts for on-site hydrogen generation from $\mathrm{NaBH}_{4}$ solution, Mater. Lett. 60 (2006) 2236-2239.

92. C. Xiang, D. Jiang, Z. She, Y. Zou, H. Chu, S. Qiu, H. Zhang, F. Xu, C. Tang, L. Sun, Hydrogen generation by hydrolysis of alkaline sodium borohydride using cobalt-zinc-boron/graphene nanocomposite treated with sodium hydroxide, Int. J. Hydrogen. Energy 40 (2015) 4111-4118.

93. E. Özdemir, Enhanced catalytic activity of Co-B/glassy carbon and Co-B/graphite catalysts for hydrolysis of sodium borohydride, Int. J. Hydrogen. Energy. 40 (2015)14045-14051.

94. Z. Liu, B. Guo, S.H. Chan, E.H. Tang, L. Hong, Pt and Ru dispersed on $\mathrm{LiCoO}_{2}$ for hydrogen generation from sodium borohydride solutions, J. Power. Sources 176 (2008) 306-311. 
95. B.H. Liu, Q.A. Li, A highly active Co-B catalyst for hydrogen generation from sodium borohydride hydrolysis, Int. J. Hydrogen Energy 33 (2008) 7385-7391.

96. S. Ozkar,M. Zahmakiran, Hydrogen generation from hydrolisis of sodium borohydride using $\mathrm{Ru}(0)$ nanoclusters as catalyst, J. Alloys. Compd. 404-406 (2005) 728-731.

97. S. Muir, X. Yao, Progress in sodium borohydride as a hydrogen storage material. Development of hydrolysis catalysts and reaction systems, Int. J. Hydrogen. Energ. 36 (2011) 5983-5997.

98. N. Patel, R. Fernandes, G. Guella, A. Kale, A. Miotello, B. Patton, C. Zanchetta, Structured and nanoparticle assembled Co-B thin films prepared by pulsed laser deposition: a very efficient catalyst for hydrogen production, J. Phys. Chem. C 112 (2008) 6968-6976.

99. G. Guella, C. Zanchetta, B. Patton, A. Miotello, A. New insights on the mechanism of palladiumcatalysed hydrolysis of sodium borohydride from ${ }^{11} \mathrm{~B}$ NMR measurements, J. Phys. Chem. B 110 (2006) 17024-17033. 